\title{
Numerical and Experimental Analysis on Runner and Gate Positioning for Magnesium Alloy Die-casted Test Piece
}

\author{
Mohd Danial Ibrahim, a , Ger Lian Tan, b, Lidyana Roslan, c, Yuki \\ Kashiwabara $^{2, d}$, Jasmine Jendia ${ }^{1, e}$ and Yuta Sunami $i^{3, f}$ \\ ${ }^{1}$ Department of Mechanical and Manufacturing Engineering, Universiti Malaysia Sarawak, 94300 \\ Kota Samarahan, Sarawak, Malaysia. \\ ${ }^{2}$ Graduate School of Science and Engineering, Department of Mechanical Engineering, Tokai \\ University, 4-1-1 Kitakaname, Hiratsuka, Kanagawa, Japan. \\ ${ }^{3}$ School of Science and Engineering, Department of Mechanical Engineering, Tokai University, 4-1-1 \\ Kitakaname, Hiratsuka, Kanagawa, Japan. \\ aimdanial@unimas.my, b18020160@siswa.unimas.my, crlidyana@unimas.my, \\ dy.kashiwabara.snmlab@hope.tokai-u.jp, e50552@siswa.unimas.my, fsunami@tokai-u.jp
}

Keywords: Injection molding, Runner system design, Magnesium, Optimization

\begin{abstract}
High Pressure Die Casting (HPDC) is a manufacturing process producing complex and precise products by injecting molten material into mold cavity at top speed and pressure. The quality of product is highly related with mold cavity design. Casting defects due to inappropriate mold design will affect mechanical properties, surface quality and product life cycle. Optimization of runner system is essential to manufacture complex and precision product design with minimal defects. The combination of runner and gating system is investigated in this paper. This paper investigated the effect of runner and gating optimization in reducing the gas porosity inside casting by evaluating the fluid and thermal distribution behavior in experimental and Computational Fluid Dynamic (CFD). The gas porosity generated in the molten magnesium alloy is due to the turbulent flow and the inconsistency of the fluid flow to push the gas bubble away from the main casting. This paper includes an X-ray of a sample product that shows correlation between gas porosity and CFD results. Results show that localize porosity gathered at the bottom of the main casting. Based on localized porosity position, runner and gating system is modified and numerical simulation is carried out for analysis. An inspection instrument step-type test piece is taken as an investigation sample to illustrate the technique of design modifications and improvements. Process parameters considered in this paper are injection speed, injection pressure, melt temperature and mold temperature. This paper proposed new runner designs that can generate balanced velocity and temperature distribution inside mold cavity, improving the solidification process aimed for reducing casting defects.
\end{abstract}

\section{Introduction}

The productivity performance of HPDC is high among manufacturing process especially in production line. HPDC is applicable for both ferrous and non-ferrous products [1]. The process of Metal Injection Molding (MIM) is similar to plastic injection molding, where it starts with the preparation of raw material in granular size. Granular size metal is loaded into the feeder, melted along screw-melting-cylinder and finally approaches the nozzle for injection. Molten metal granular is injected with high pressure and temperature to ensure solidification process occurs inside the casting mold effectively [2].

V-LINE@SYSTEM. Die casting machine developers realized that commercial incline screw system had issue such as material backflow and semi-filling of metal resins. V-LINE® SYSTEM separates plasticization and injection cylinder, accurately filling exact billet material and automatically cuts off supply once the volume is enough, finally injecting molten metal into the mold cavity [3]. This technological advancement enables stable and consistent volume filling for every cycle, allowing researchers to identify the porous location and factors effectively. This system is 